\title{
The effect of the tongue in groove technique on the nasolabial angle and nasal tip projection
}

\author{
Fatemeh Khabir ${ }^{1}$, Mehdi Sezavar² ${ }^{2 *}$, Behnam Bohluli ${ }^{2,3}$, Vahid Mesgarzadeh² and Hamidreza Tavakoli ${ }^{1}$
}

\begin{abstract}
Background: The tongue in groove technique (TIG) is a useful technique for the correction of the nasal tip projection and the nasolabial angle. The purpose of this study was to determine the utility of this technique for nasal tip rotation and projection correction in the Iranian society.

Methods: This is a retrospective clinical trial study of 20 patients undergoing open septo-rhinoplasty using TIG technique from January 2017 to August 2019 at the oral and maxillofacial unit of Bu Ali Hospital and private sector. Preoperative and postoperative profile view photographs were compared to assess the changes in tip projection and rotation.

Results: Fifteen patients (75\%) had normal angular size, and 5 of them (25\%) were not within the normal range after the surgery. The Fisher exact test showed that this success was statistically significant $(P=0.006)$. Ten patients $(50 \%)$ had normal projection size, postoperatively. The Fisher exact test showed that this effect was statistically significant $(P<0.01)$
\end{abstract}

Conclusion: The study demonstrated the benefit of TIG on the correction of nasal tip projection and rotation.

Keywords: Rhinoplasty, Tongue in groove technique (TIG), Nasal tip projection, nasolabial angle

\section{Background}

One of the most challenging surgeries in the field of aesthetic is rhinoplasty $[1,2]$, among many useful methods providing desired results, tongue in groove (TIG) is a strong suture technique allowing conservative surgery to manage tip projection and rotation [3]. This method has been performed to correct the caudal septum deviation, as well as excessive columellar show [4]. It can be used in either open or closed rhinoplasty.

The axiom in this approach is adopting and relocating the medial crura in its right, stable position before suturing is performed $[2,5]$. The extension of cartilaginous septum will be placed in a groove surgically created

\footnotetext{
* Correspondence: Drmehdisezavar@gmail.com

2Department of Oral and Maxillofacial Surgery, Craniomaxillofacial Research Center, Bu Ali Hospital, Islamic Azad University, No. 17, Golestan Alley,

Shahrak Gharb Ave, Tehran, Iran

Full list of author information is available at the end of the article
}

between the medial crura (Fig. 1). The suture position has a very important role in rotation and projection of the nasal tip [2]. A more superior position of the suture along the vertical axis of the septum results in projection and rotation increase. Also, the movement of the suture along the horizontal axis of the septum will cause increase in nasal tip rotation with no nasal projection changes.

Although the literature show the effectiveness of this technique in European and American human studies [1, 6], we failed to find an article assessing the efficacy of this method in the Iranian society; so the aim of this study was to confirm this effectiveness through a clinical study.

\section{Methods}

Through the present study of a consecutive series of patients, undergoing primary septo-rhinoplasty in $\mathrm{Bu}$ Ali Hospital and private clinics from January 2017 to August 2019, we performed the TIG technique on 20 patients

\section{Springer Open}

(c) The Author(s). 2020 Open Access This article is licensed under a Creative Commons Attribution 4.0 International License, which permits use, sharing, adaptation, distribution and reproduction in any medium or format, as long as you give appropriate credit to the original author(s) and the source, provide a link to the Creative Commons licence, and indicate if changes were made. The images or other third party material in this article are included in the article's Creative Commons licence, unless indicated otherwise in a credit line to the material. If material is not included in the article's Creative Commons licence and your intended use is not permitted by statutory regulation or exceeds the permitted use, you will need to obtain permission directly from the copyright holder. To view a copy of this licence, visit http://creativecommons.org/licenses/by/4.0/. 


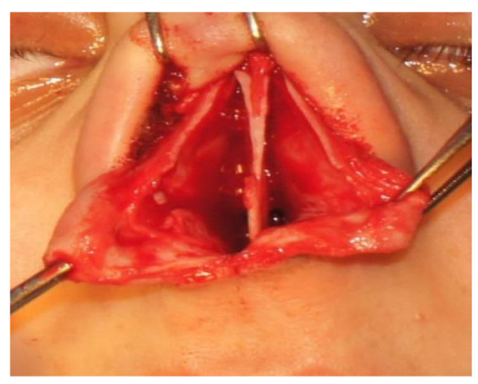

a

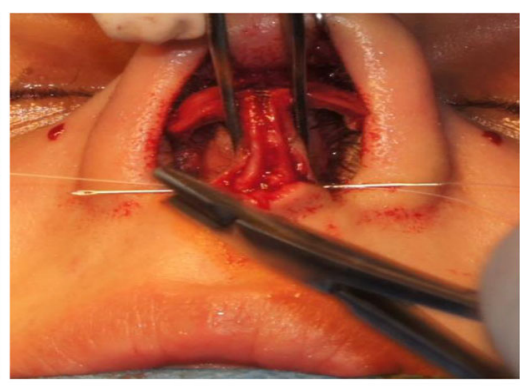

b

Fig. 1 Surgical procedure. a It shows a membranous septum detachment, exposing the septum between the medial crura. $\mathbf{b}$ It refers to perform suturing of the medial crura and the septum together

having tip deformities in their preoperative documents. Ethical approval was given in May 27, 2018, by the research ethics committee of Islamic Azad University, Tehran Branch (approval ID is IR.IAU.DENTAL.REC.1397.022). Hiring this ethical approval and based on the consent form for each patient, we performed this study.

We analyzed photographs of 2 men and 18 women aged between 18 and 55. Exclusion criteria were as follows: the history of previous septo-rhinoplastic surgery, trauma to the nose, normal range of nasolabial angle $\left(90-110^{\circ}\right)$, and normal tip projection according to the Goode method assessment (55-60\%) [3]. Also, any jaw deformity requiring orthognathic surgery and any craniomaxillofacial syndrome causing nose deformation were excluded.

Profile view photographs were taken pre- and postsurgery according to the standardized clinical photography (1:1) (Fig. 2). Evaluation of the nasolabial angle by using the Golden Rhino Software and the Goode method for measuring nose projection was performed. All patients were followed up at least for 6 months. Nasolabial angle and nasal tip projection changes were judged by statistical testing named the Fisher exact test.

\section{Result}

The study was designed to assess the effect of TIG on nasolabial angle and tip projection changes in the Iranian society. Twenty eligible patients including 18 women and 2 men aged between 18 and 55 underwent open septo-rhinoplasty surgery. None of the patients had a history of rhinoplasty, nasal trauma, and jaw and craniomaxillofacial abnormalities.

The distribution of nasolabial angle in patients before and after TIG surgery show that before surgery, all patients had a nasolabial angle size out of the normal range (Table 1). In the postoperative period, 15 patients (75\%) had normal angular size. The Fisher exact test showed that this success was statistically significant after treatment $(P=0.006)$.

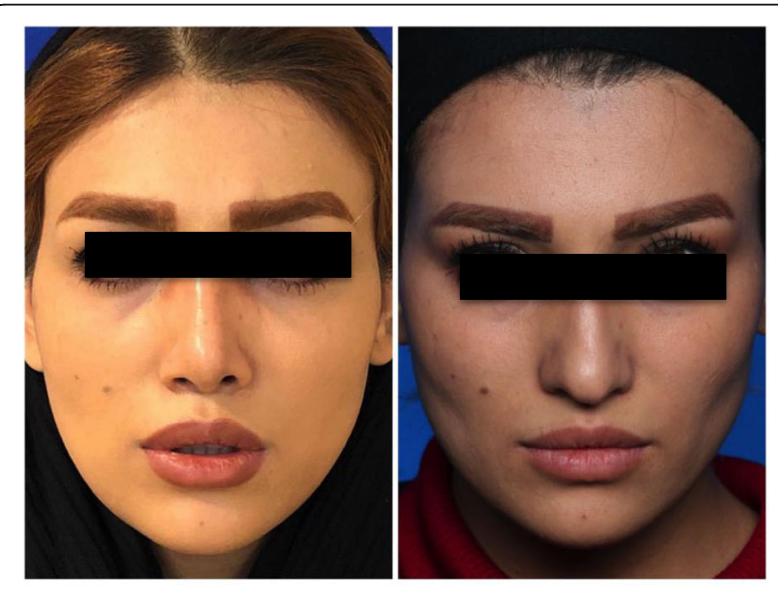

a
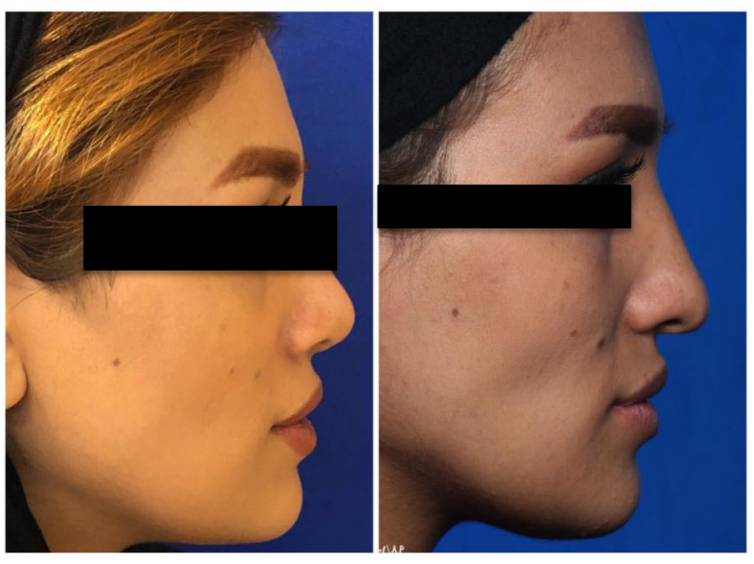

b

Fig. 2 Clinical presentation before and after surgery. a Frontal view before and after surgery. $\mathbf{b}$ Lateral view before and after surgery 
Table 1 Distribution of patients undergoing rhinoplasty in terms of nasolabial angle before and after surgery

\begin{tabular}{llll}
\hline & Normal range & Out of normal range & $P$ value \\
\hline Before surgery & 0 & 20 & 0.006 \\
After surgery & 15 & 5 & \\
\hline
\end{tabular}

Pre- and postoperative results of nasal tip projection and their comparison showed that prior to surgery, none of the patients' tip position were within the normal range. Postoperatively, 10 patients $(50 \%)$ had normal projection size (Table 2). The Fisher exact test showed that this effect was statistically significant $(P<0.01)$.

\section{Discussion}

Despite technical advances, rhinoplasty has progressed with an inclination toward minimally invasive surgical techniques. TIG technique is one of the most successful procedures and also a non-aggressive one. This method is first described by Kridel et al. [7] in 1999 and continued by Shah and Miller [8], then followed by Toriumi [2] and Guyuron and Brow [3]. The positive effect of TIG is determined in tip deformities and septal deviation of the lower third part of the nose and columellar show, which had a remarkable and excellent functional and aesthetic outcome and long-lasting support [7].

In contrast to previously described techniques, TIG does not rely on graft harvesting for placement between the medial crura, yet even can play its role in tip projection and nasolabial angle rotation as well as septal deviation successfully $[9,10]$. In addition to the mentioned advantages, tip rotation can perform more controlled than routine maneuvers, based on unexpected contracture to gain a proper tip $[6,11]$. Patients did not complain any abnormal rigid sensation in the subnasal because of the columellar graft application. Caudal septal deviation also can be corrected without any excision in the septum which may lead to droopy nose deformity $[12,13]$.

Recently, Lohuis and Datema [6] published a description of TIG advantages in revision rhinoplasty which can be performed in combination with graft augmentation. As a result, TIG is a valuable multi-purpose technique which can be used for correction of excessive columellar show, short nose, droopy nose, reformation of septal deviation, tip plasty in association to improving nasolabial angle, and tip projection correction [5, 14].

Table 2 Distribution of patients undergoing rhinoplasty in terms of nasal tip projection before and after surgery

\begin{tabular}{llll}
\hline & Normal range & Out of normal range & $P$ value \\
\hline Before surgery & 0 & 20 & $<0.01$ \\
After surgery & 10 & 10 & \\
\hline
\end{tabular}

In our study, which is the first published data describing the effectiveness of this method, advantages of TIG in the correction of nasolabial angle and nasal tip projection in the Iranian society had its reproducibility as well as predictability (Tables 1 and 2). The most critical advantage of this method is that we can still choose a minimally invasive technique such as TIG suturing which may be laid in modern rhinoplastic techniques.

\section{Conclusion}

Finally, TIG is a predictable technique and has high success rate which can adjust the medial crura in a proper position in respect to the septum as a tongue. It can be recognized as a long-lasting stable method with appropriate functional and aesthetic results.

\section{Acknowledgments}

Not applicable.

\section{Authors' contributions}

The whole course of the research was done with the cooperation and consent of all the participants.

\section{Funding}

Not applicable.

\section{Availability of data and materials}

Data in the Iranian society was not available.

\section{Ethics approval and consent to participate}

Ethical approval was given in May 27, 2018, by the research ethics committee of Islamic Azad University, Tehran Branch, and the approval ID is

IR.IAU.DENTAL.REC.1397.022. So, with this ethical approval and based on the consent forms for each patient, we began the study.

\section{Consent for publication}

Consent forms were given to 20 patients in order to do the surgery and plans for the research.

\section{Competing interests}

Not applicable.

\section{Author details}

${ }^{1}$ Department of Oral and Maxillofacial Surgery, Bu Ali Hospital, Islamic Azad University, Tehran, Iran. ${ }^{2}$ Department of Oral and Maxillofacial Surgery, Craniomaxillofacial Research Center, Bu Ali Hospital, Islamic Azad University, No. 17, Golestan Alley, Shahrak Gharb Ave, Tehran, Iran. ${ }^{3}$ Department of Oral and Maxillofacial Surgery, University of Toronto, Toronto, Canada.

Received: 24 January 2020 Accepted: 11 May 2020

Published online: 08 June 2020

References

1. Ponsky CD, Harvey JD, Khan WS, Guyron B (2010) Nose elongation: a review and description of the septal extension tongue and groove technique. Aesthet Surg 30(3):335-346

2. Toriumi DM (2006) New concepts in nasal tip contouring. Arch Facial Plast Surg 8(3):156-185

3. Guyuron B, Brow M (2013) Redefining the ideal nasalobial angle: part 2. Expert analysis. Plast Reconstr Surg 132(2): 221e-225e.

4. Guyuron B, Varghai A (2003) Lengthening the nose with a tongue-andgroove technique. Plast Reconstr Surg 111(4):1533-1539

5. Datema FR, Lohuis PJ (2016) The tongue-in-groove technique in primary and revision rhinoplasty. Facial Plast Surg 32(4):416-423

6. Lohuis PJ, Datema FR (2015) Patient satisfaction in Caucasian and Mediterranean open rhinoplasty using the tonque-in-groove technique: prospective statistical analysis of change in subjective body image in 
relation to nasal appearance following aesthetic rhinoplasty. Laryngoscope 125(4):831-836

7. Kridel RW, Scott BA, Foda HM (1999) The tongue-in-groove technique in septorhinoplasty. A 10-year experience. Arch Facial Plast Surg 1(4):246-256

8. Shah AR, Miller PJ (2006) Structural approach to endonasal rhinoplasty. Facial Plast Surg 22(1):55-60

9. Foda HM (2003) Management of the droopy tip; a comparison of three alar cartilage-modifying techniques. Plast Reconstr Surg 112(5):1408-1417

10. Margulis A, Harel M (2007) Management of severe tip ptosis in closed rhinoplasty: the horizontal columellar strut. J Plast Reconstr Aesthet Surg 60(4):400-406

11. Persichetti $P$, Toto V, Signoretti M, Del Buono R, Brunetti B, Segreto D et al (2013) The correction of nasal septal deviations in rhinoplasty. Ann Oral Maxillofac Surg 1(2):13

12. Katira K, Guyuron B (2015) Contemporary techniques for effective nasal lengthening. Facial Plast Surg Clin North Am 23(1):81-91

13. Kadakia S, Ovchinsky A (2016) Comparison of permanent versus absorbable suture in the tongue-in-groove technique in endonasal rhinoplasty. Am J Cosmet Surg 33(2):91-95

14. Giacomini PG, Rubino S, Mocella S, Pascal M, Di Girolamo S (2017) Approach to the correction of drooping tip: common problems and solutions. Acta Othorhinolaryngol Ital 37(4):295-302

\section{Publisher's Note}

Springer Nature remains neutral with regard to jurisdictional claims in published maps and institutional affiliations.

\section{Submit your manuscript to a SpringerOpen ${ }^{\circ}$ journal and benefit from:}

- Convenient online submission

- Rigorous peer review

- Open access: articles freely available online

- High visibility within the field

- Retaining the copyright to your article 